\title{
The Effect of CTAB on the Citrate Sol-gel Process for the Synthesis of Sodium Beta-Alumina Nano-Powders
}

\author{
Zaihua Wang, ${ }^{\dagger, \star}$ Xinjun $\mathrm{Li}^{\dagger}{ }^{\dagger}$ and Ziping Feng ${ }^{\dagger, *}$ \\ ${ }^{\dagger}$ Key Laboratory of Renewable Energy and Gas Hydrate, Institute of Energy Conversion, Chinese Academy of Sciences, \\ Guangzhou 510640, China. ${ }^{*}$-mail: fengzp@ms.giec.ac.cn \\ *Graduate University of the Chinese Academy of Sciences, Beijing 100049, China \\ Received November 29, 2010, Accepted February 22, 2011
}

\begin{abstract}
Sodium beta-alumina (SBA) nano-powders were synthesized by the citrate sol-gel process, and the effects of the cationic surfactant $n$-cetyltrimethylammonium bromide surfactant (CTAB) were investigated. The structure and morphology of the nano-powders were characterized by X-ray diffraction (XRD) and transmission electron microscope (TEM) techniques, respectively. The effects of CTAB on the citrate sol-gel process and the SBA formation were investigated by thermo gravimetric/differential thermal analysis (TG/DTA) and Fourier transform infrared spectroscopy (FTIR). The conductivity of ceramic pellets of SBA was measured by electrochemical impedance spectroscopy (EIS). The results showed that the CTAB inhibited the agglomeration of SBA powders effectively and consequently decreased the crystallization temperature of SBA, about $150{ }^{\circ} \mathrm{C}$ lower than that of the sample without CTAB. The measured conductivity of SBA was $1.21 \times 10^{-2} \mathrm{~S} \cdot \mathrm{cm}^{-1}$ at $300^{\circ} \mathrm{C}$.
\end{abstract}

Key Words : Sodium beta-alumina, Surfactant, Sol-gel, Nano-powders

\section{Introduction}

Sodium beta-alumina (SBA) is well known as an efficient sodium ion conductor that can be used as the solid electrolyte in sodium-sulfur batteries. ${ }^{1}$ Various methods have been developed for fabricating SBA powders. Conventionally, SBA powder was synthesized by the solid-state reaction of $\alpha$-alumina with $\mathrm{Na}_{2} \mathrm{CO}_{3}$ and small amounts of $\mathrm{MgO}$ and/ or $\mathrm{Li}_{2} \mathrm{O}$ as stabilizing agent. ${ }^{2,3}$ Other different methods were also employed, such as alkoxide hydrolysis, ${ }^{4,5}$ sol-gel processing, ${ }^{6-8}$ co-precipitation ${ }^{9,10}$ and solution combustion technique. ${ }^{11}$ Among the different chemical routes, the citrate solgel method has received considerable attention because of its advantages such as excellent product homogeneity, better compositional control and lower processing temperature. ${ }^{12}$ In this route, metallic complexes were prepared from an aqueous solution and then heated till forming a highly viscous gel. Finally, the precursor powders resulting from the pyrolysis of gel were calcined at high temperature to the formation of the SBA.

The SBA ceramic tube is one key component in sodiumsulfur battery and its quality affects the life and the performance of the battery. The fabrication of the fine dispersion SBA ceramic nano-powders is one of the preconditions to obtain the satisfactory SBA ceramic tubes with higher sintering density and lower sintering temperature. In this work, the SBA nano-powders were synthesized by a citrate sol-gel method and the influences of the CTAB surfactant on the formation of SBA were studied.

\section{Experimental Section}

Preparation of SBA Nano-Powders. The SBA nano- powders were prepared using the citrate sol-gel method. A.R. grade aluminum nitrate nonahydrate $\left(\mathrm{Al}\left(\mathrm{NO}_{3}\right)_{3} \cdot 9 \mathrm{H}_{2} \mathrm{O}\right)$, magnesium nitrate hexahydrate $\left(\mathrm{Mg}\left(\mathrm{NO}_{3}\right)_{2} \cdot 6 \mathrm{H}_{2} \mathrm{O}\right)$, sodium nitrate $\left(\mathrm{NaNO}_{3}\right)$, citrate acid (CA), ethylene glycol (EG) and $n$-cetyltrimethylammonium bromide surfactant (CTAB) were used as starting materials without further purification. In a typical synthesis process, first, appropriate amounts of CTAB were dissolved into distilled water with magnetic stirring. In the second step, appropriate amounts of $\mathrm{Al}\left(\mathrm{NO}_{3}\right)_{3} \cdot 9 \mathrm{H}_{2} \mathrm{O}$, $\mathrm{Mg}\left(\mathrm{NO}_{3}\right)_{2} \cdot 6 \mathrm{H}_{2} \mathrm{O}$ and $\mathrm{NaNO}_{3}$ were dissolved into distilled water to form the solution (A) with a molar ratio of 10.33: $0.67: 1.67$, then citric acid and ethylene glycol were added into the solution (A) to form the uniform solution (B), and the molar ratio of citric acid to metallic ions and ethylene glycol was $1: 1: 4$. In the third step, the CTAB solution was added into the solution (B) drop by drop with vigorous stirring. The molar ratios of CTAB to metallic ions were 0.1 , 0.2 and 0.4 , respectively. And then, the resulting solutions were slowly evaporated in a water bath of $80^{\circ} \mathrm{C}$ with stirring until the formation of light yellow transparent gels. Finally, the gels were transferred into a pre-heated muffle oven at $500{ }^{\circ} \mathrm{C}$, the combustion took place accompanied with the liberation of a large amount of gases, and then the fluffy powders were formed after several minutes. Following that, the formed fluffy powders were then calcined at 900-1100 ${ }^{\circ} \mathrm{C}$. For comparison, the sample without CTAB was also prepared using a similar process.

Preparation of SBA Ceramic Pellets. The obtained SBA nano-powders were pressed uniaxially at $100 \mathrm{MPa}$ to pellets (13 $\mathrm{mm}$ diameter, $2 \mathrm{~mm}$ thickness). The pellets were finally sintered in air at $1400{ }^{\circ} \mathrm{C}$ for $2 \mathrm{~h}$. The pellets were embedded in the SBA nano-powders for avoiding the lost of $\mathrm{Na}_{2} \mathrm{O}$.

Characterizations. The crystal phase identifications of 
the samples were performed by X-ray diffraction (XRD, $\mathrm{X}^{\prime}$ Pert-Pro, Panalytical Incorporated, Holland) equipped with $\mathrm{Cu} \mathrm{K} \alpha$ radiation at an accelerating voltage of $40 \mathrm{kV}$ and a current of $40 \mathrm{~mA}$. The morphology of the samples was observed by transmission electron microscope (TEM, JEM1010, Leica Incorporated, Japan) operated at $100 \mathrm{kV}$. Thermo gravimetric (TG) and differential thermal analysis (DTA) were measured by a thermo gravimetric analyzer (TG, STA 409C/PC, NETZSCH Incorporated, Germany) at a heating rate of $10{ }^{\circ} \mathrm{C} / \mathrm{min}$ in a dry air flow $(30 \mathrm{~mL} / \mathrm{min})$. Fourier transform infrared (FTIR) spectra were collected over Tensor 27 spectrometer (Bruker Optics), using 32 scans per spectrum in the region of $4000-600 \mathrm{~cm}^{-1}$ with a resolution of $4 \mathrm{~cm}^{-1}$. The ionic conductivity of the sintered pellets at $300{ }^{\circ} \mathrm{C}$ in air were measured using an impedance analyzer (CHI 606A, Shanghai Chenhua) in the frequency range $10^{5}-1 \mathrm{~Hz}$, and a $5 \mathrm{mV} \mathrm{AC}$ signal was applied. To prepare samples for the ionic conductivity measurements, $\mathrm{Pt}$ paste was painted on both sides of the pellets, and then annealed at $900{ }^{\circ} \mathrm{C}$ for $1 \mathrm{~h}$ to remove the residual organics. Before the measurements, the samples were held in a tube furnace for temperature equilibrium.

\section{Results and Discussion}

The XRD patterns of the samples calcined at different temperatures were shown in Figure 1 to Figure 4. All samples were calcined for $2 \mathrm{~h}$. At the calcination temperature of 900 ${ }^{\circ} \mathrm{C}$, as shown in Figure 1, there were no differences for the samples with and without CTAB. It was a mixture of $\mathrm{Na}_{2} \mathrm{Al}_{2 \mathrm{x}} \mathrm{O}_{3 \mathrm{x}+1}$ and $\mathrm{MgAl}_{2} \mathrm{O}_{4}$. With the calcination temperature increasing to $1000{ }^{\circ} \mathrm{C}$, the results were shown in figure 2. The major phase was the SBA for the sample with CTAB, but the phases of $\mathrm{Na}_{2} \mathrm{Al}_{2 \mathrm{x}} \mathrm{O}_{3 \mathrm{x}+1}$ and $\mathrm{MgAl}_{2} \mathrm{O}_{4}$ could also be detected. While there was no SBA phase formed for the sample without $\mathrm{CTAB}$, the phases consisted of $\mathrm{Na}_{2} \mathrm{Al}_{2 \mathrm{x}} \mathrm{O}_{3 \mathrm{x}+1}$ and $\mathrm{MgAl}_{2} \mathrm{O}_{4}$, and the peak intensity of $\mathrm{MgAl}_{2} \mathrm{O}_{4}$ was lower than the sample calcined at $900{ }^{\circ} \mathrm{C}$. XRD patterns of the samples calcined at $1050{ }^{\circ} \mathrm{C}$ were shown in Figure 3. For the

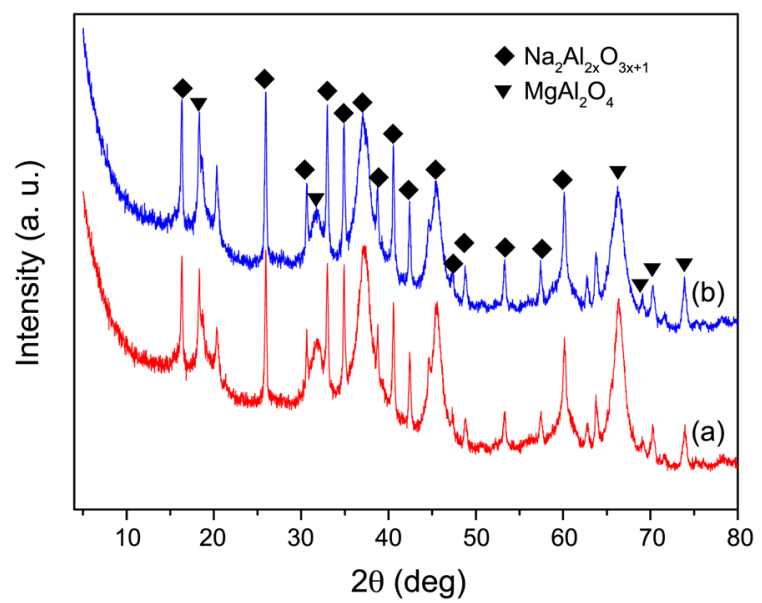

Figure 1. XRD patterns of the samples calcined at $900{ }^{\circ} \mathrm{C}$ : (a) without; (b) with $\mathrm{CTAB}(\mathrm{CTAB} /$ total metallic ions $=0.2$, molar ratio). sample with CTAB, the major phase was SBA and also a little $\mathrm{Na}_{2} \mathrm{Al}_{2 \mathrm{x}} \mathrm{O}_{3 \mathrm{x}+1}$ phase was detected. For the sample

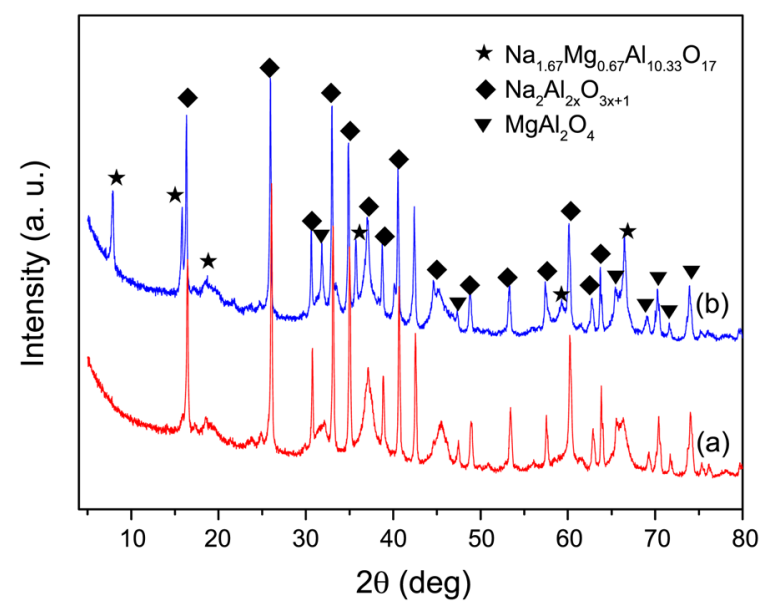

Figure 2. XRD patterns of the samples calcined at $1000{ }^{\circ} \mathrm{C}$ : (a) without $\mathrm{CTAB}$; (b) with $\mathrm{CTAB}(\mathrm{CTAB} /$ total metallic ions $=0.2$, molar ratio).

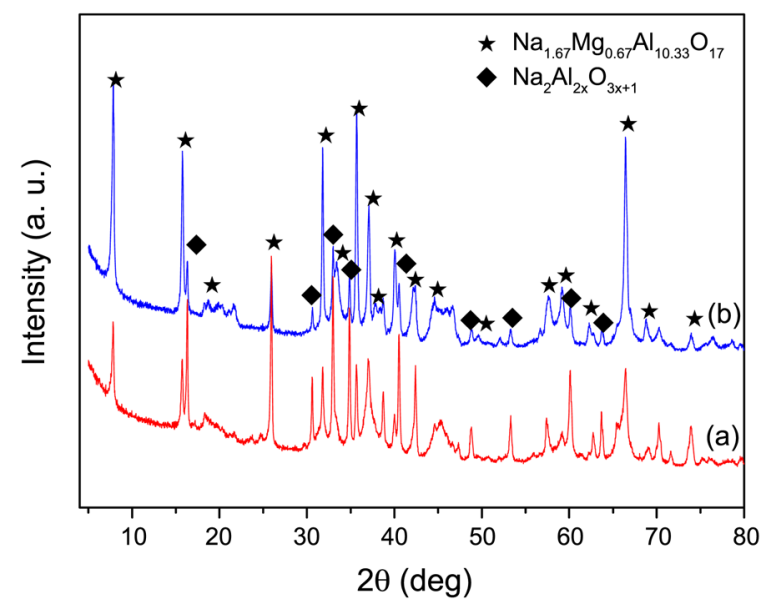

Figure 3. XRD patterns of the samples calcined at $1050{ }^{\circ} \mathrm{C}$ : (a) without $\mathrm{CTAB}$; (b) with $\mathrm{CTAB}(\mathrm{CTAB} /$ total metallic ions $=0.2$, molar ratio).

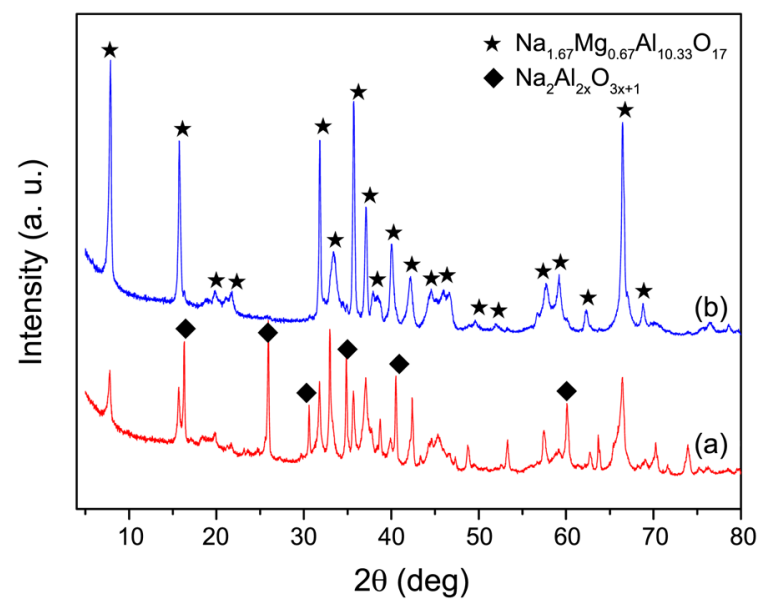

Figure 4. XRD patterns of the samples calcined at $1100{ }^{\circ} \mathrm{C}$ : (a) without CTAB; (b) with CTAB (CTAB/total metallic ions $=0.2$, molar ratio). 

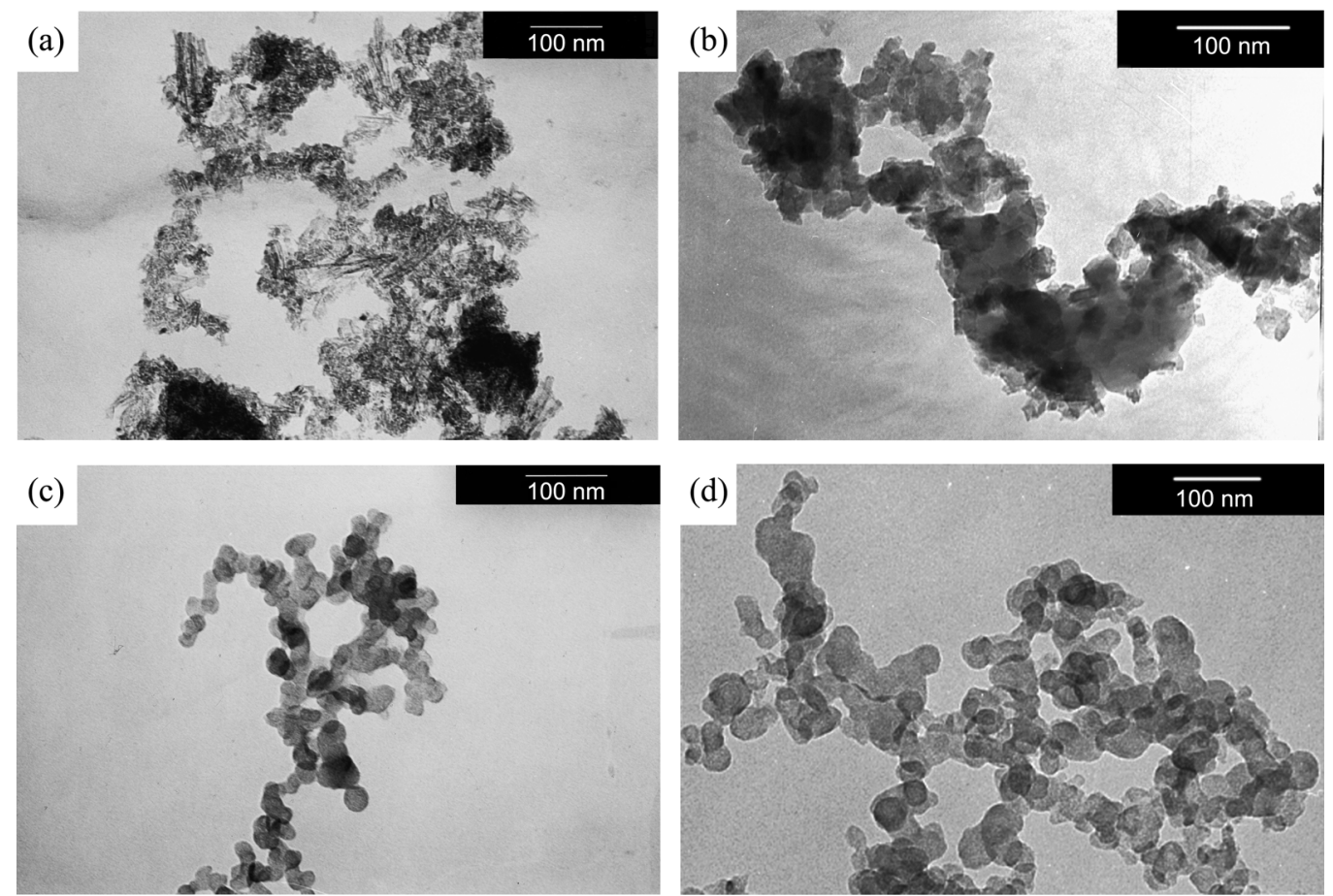

Figure 5. TEM images of the SBA powders calcined at $1100{ }^{\circ} \mathrm{C}$ with different amounts of $\mathrm{CTAB}(\mathrm{CTAB} /$ total metallic ions, molar ratio): (a) 0 ; (b) 0.1 ; (c) 0.2 ; (d) 0.4 .

without CTAB, a mixed phase of $\mathrm{SBA}$ and $\mathrm{Na}_{2} \mathrm{Al}_{2 \mathrm{x}} \mathrm{O}_{3 \mathrm{x}+1}$ was detected. In Figure 4, the single phase of SBA was formed for the sample with $\mathrm{CTAB}$ at $1100{ }^{\circ} \mathrm{C}$. However, for the sample without $\mathrm{CTAB}$, it was a mixture phase of SBA and $\mathrm{Na}_{2} \mathrm{Al}_{2 \mathrm{x}} \mathrm{O}_{3 \mathrm{x}+1}$. All of these indicated that the CTAB could decrease the crystallization temperature of SAB effectively. The result was consistent with the TG/DTA data in Figure 8. The mean diameter of SBA crystallites in powders, calculated by the Scherrer equation, was about $24 \mathrm{~nm}$.

The TEM images of the SBA powders calcined at $1100^{\circ} \mathrm{C}$ with different amounts of $\mathrm{CTAB}$ and without $\mathrm{CTAB}$ were shown in Figure 5. The particles of the sample without $\mathrm{CTAB}$ appeared bound together into agglomerates with different shapes and sizes, even some rod-like particles were formed as shown in Figure 5(a). The variation in the shape and size of the SBA particles was the consequences of the reaction conditions during the synthesis process. The chelates of metal ions and the citrate acid were in one random condition without CTAB. When the organic compounds were removed during the combustion process, the metal ions reacted with each other to form SBA particles without any restraint, and then the particles grew up randomly to different shapes and sizes.

When 0.1 molar ratio of CTAB was added, as shown in Figure 5(b), the shape of the particles improved and approached to spherical morphology, but the agglomeration was also serious. When the molar ratios of CTAB increased to 0.2 and 0.4 , the spherical morphology improved further and the agglomeration decreased, and there was not much difference between them, as shown in Figure 5(c)-(d). The particle sizes of the samples $c$ and $d$ were in the range 20-30 $\mathrm{nm}$, and the particles were highly dispersed and crystallized. The results proved that the cationic surfactant CTAB could inhibit the agglomeration of the SBA nano-powders effec-
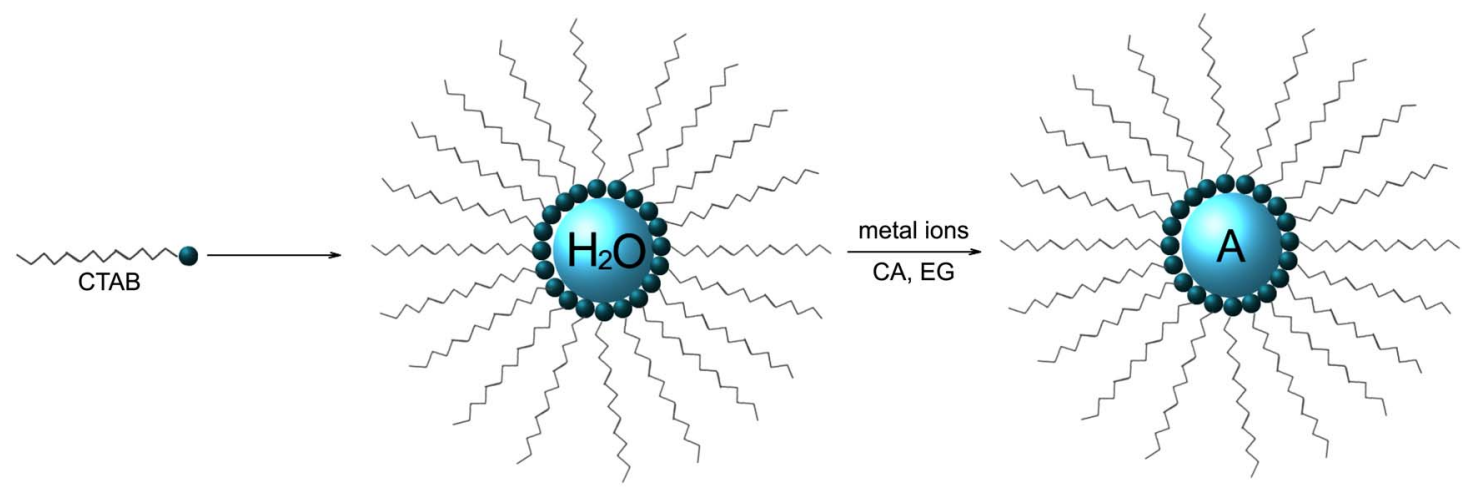

Figure 6. Schematic model of the reverse micro emulsions (A represents the chelates of metal ions with the citrate acid). 
tively. The particle size and the agglomeration depend mainly on the way of the combustion propagates and the amount of disintegration occurs. CTAB, acted as a fuel and a source of carbon, made the dry gel more porous and forced the combustion process to proceed quickly after it was added. Especially the excess fuel might act as a space filling agent, which would leave empty spaces as fuel burns during the reaction. Increasing the fuel content would further cause more gas liberation, which helped to disintegrate the agglomerates into nano-particles and reduce their subsequent growth. The spherical nature of the SBA nano-particles prepared with CTAB may be attributed to the formation of spherical micelles in the gel. The addition of cationic surfactant with amphiphilic molecules into precursor solution could form the reverse micro emulsions in the sol as shown in Figure 6 . These reverse micro emulsions offered a confined micro environment for the formation of nano-powders and as a result inhibited their excess growth and agglomeration. The sol-gel method with the addition of cationic surfactant has been proven to be an efficient method to fabricate fine nano-powders with narrow particle size distribution and low agglomeration.

Figure 7 showed the FTIR spectra of the dried gels. The peak at $3440 \mathrm{~cm}^{-1}$ was related to the stretching vibration of hydroxyl. The peaks at $2920 \mathrm{~cm}^{-1}$ and $2855 \mathrm{~cm}^{-1}$ could be attributed to the anti-symmetric and symmetric $-\mathrm{CH}_{2}-$ vibrations of the carbon chains of CTAB, respectively. The peaks at $1736 \mathrm{~cm}^{-1}$ and $1635 \mathrm{~cm}^{-1}$ corresponding to carboxyl of citric acid were weaker in the samples with CTAB than that of the ones without CTAB. The peak at $1380 \mathrm{~cm}^{-1}$ relating to nitrates showed the same properties. It proved that the CTAB could promote the complexation of citric acid with metallic ions and nitrates during the process of the preparation of SBA. The peak at $1465 \mathrm{~cm}^{-1}$ was related to the scissor bending vibration of $\mathrm{CH}_{2}$ groups. The peaks at $1400 \mathrm{~cm}^{-1}, 1200 \mathrm{~cm}^{-1}$ and $1080 \mathrm{~cm}^{-1}$ were due to the $\mathrm{C}-\mathrm{H}$ deformation of $\mathrm{CH}_{2}$ groups of ethylene glycol.

The DTA curves of the gels with the different molar ratio of CTAB to total metallic ions were shown in Figure 8. The

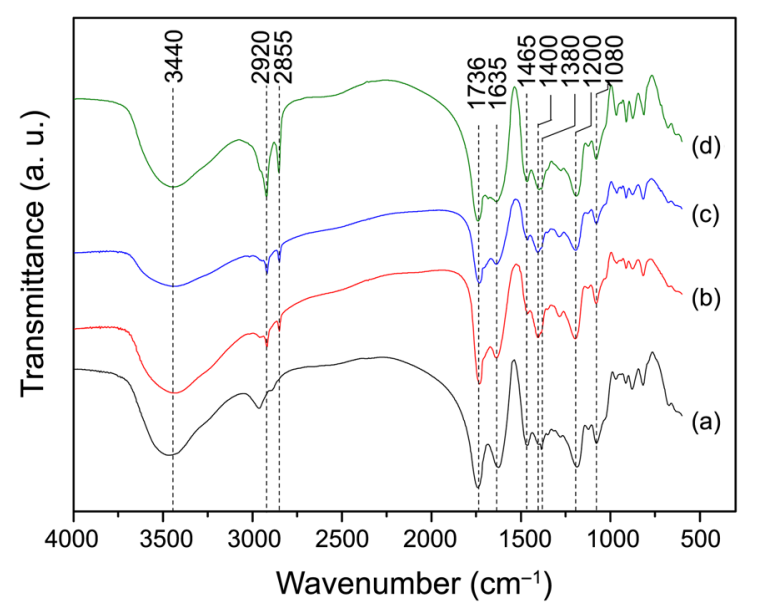

Figure 7. FTIR spectra of the dried gels with different amounts of CTAB: molar ratio of CTAB/total metallic ions is (a) 0 ; (b) 0.1 ; (c) 0.2 ; (d) 0.4 .

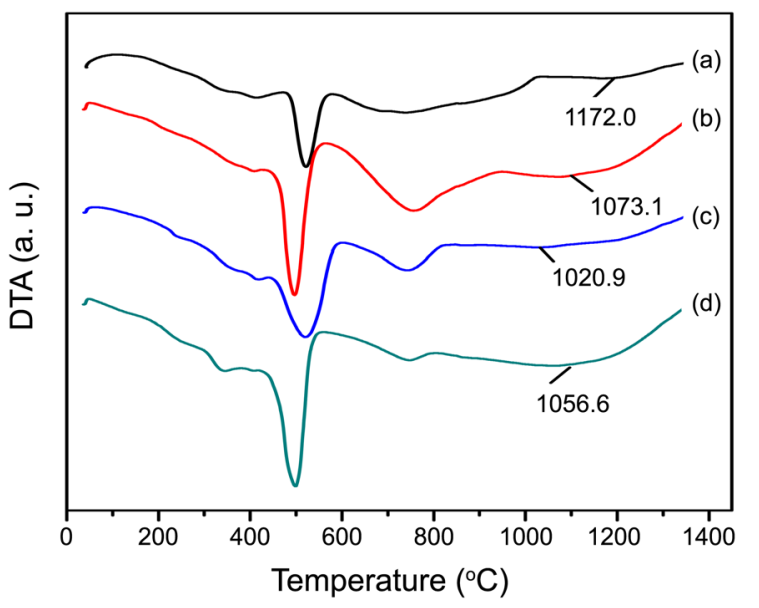

Figure 8. DTA curves of the dried gels with different amounts of CTAB: molar ratio of CTAB/total metallic ions is (a) 0 ; (b) 0.1 ; (c) $0.2 ;(d) 0.4$.

TG curves of the four samples were not shown as the results were similar. At the temperatures between $40^{\circ} \mathrm{C}$ and $600{ }^{\circ} \mathrm{C}$, large mass losses were observed for all the samples. The endothermic peak at about $150{ }^{\circ} \mathrm{C}$ was associated with the evaporation of physical adsorbed water or residual solvents. The two exothermic peaks at about $500{ }^{\circ} \mathrm{C}$ and $750{ }^{\circ} \mathrm{C}$ were attributed to the removal of the residual organic groups. The exothermic peak above $1100{ }^{\circ} \mathrm{C}$ without weight losses was due to the crystalline phase transformation from $\mathrm{Na}_{2} \mathrm{Al}_{2 \mathrm{x}} \mathrm{O}_{3 \mathrm{x}+1}$ to SBA. When the molar ratio of CTAB to total metallic ions equaled to 0.2 , the crystallization temperature was about 150 ${ }^{\circ} \mathrm{C}$, which was lower than that of the sample without CTAB, as shown in Figure 8. These results further established that the CTAB could reduce the crystallization temperature of SBA effectively.

Figure 9 showed the AC impedance spectra of SBA ceramic pellets at $300{ }^{\circ} \mathrm{C}$. The intercept of the semicircle with the real axis represented the ohmic resistance of the SBA ceramic pellets. The conductivity of the sample without

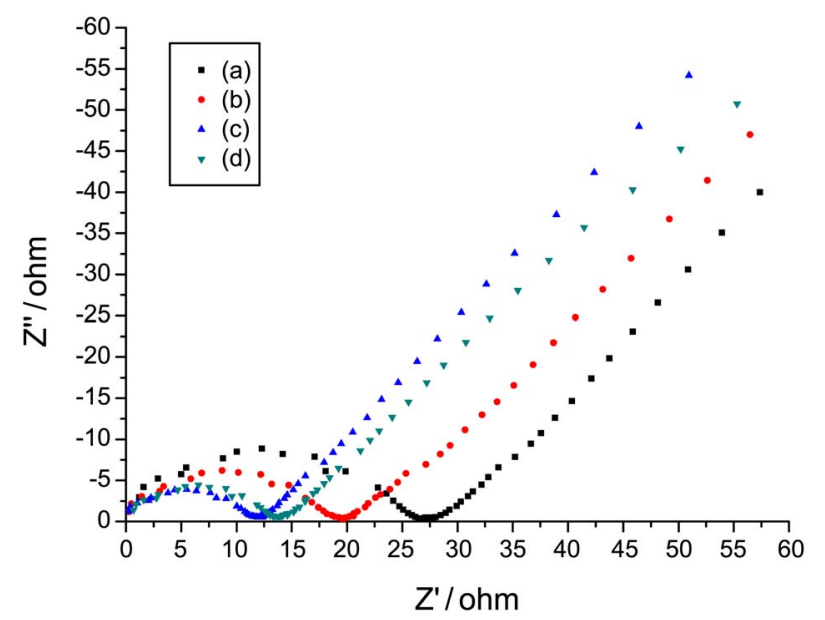

Figure 9. AC impedance spectra of SBA pellets calcined at $300{ }^{\circ} \mathrm{C}$ with different amounts of CTAB: molar ratio of $\mathrm{CTAB} /$ total metallic ions is (a) 0 ; (b) 0.1 ; (c) 0.2 ; (d) 0.4 . 
CTAB was $5.48 \times 10^{-3} \mathrm{~S} \cdot \mathrm{cm}^{-1}$. With 0.1 molar ratio CTAB added, the conductivity of the sample increased to $7.54 \times$ $10^{-3} \mathrm{~S} \cdot \mathrm{cm}^{-1}$. With more CTAB added, the conductivity increased further to $1.21 \times 10^{-2} \mathrm{~S} \cdot \mathrm{cm}^{-1}$ and $1.10 \times 10^{-2}$ $\mathrm{S} \cdot \mathrm{cm}^{-1}$ for the samples with 0.2 and 0.4 molar ratio CTAB, respectively. It showed that the nano-powders prepared using CTAB could enhance the conductivity of the SBA ceramic pellets. The conductivity value was higher than the value reported by Subasri. ${ }^{8}$

\section{Conclusion}

Sodium beta-alumina (SBA) nano-powders were synthesized using the citrate sol-gel process with the addition of surfactant CTAB. The results showed that the addition of CTAB inhibited the agglomeration of SBA powders effectively and decreased the crystalline temperature of SBA, about $150^{\circ} \mathrm{C}$ lower than that of the sample without CTAB. The particle size was in the range of $20-30 \mathrm{~nm}$. It proved that the surfactant CTAB had the positive effect on the synthesis of fine SBA nano-powders. The highest conductivity of the SBA ceramic pellets was $1.21 \times 10^{-2} \mathrm{~S} \cdot \mathrm{cm}^{-1}$.
Acknowledgments. The authors wish to express their sincere appreciation for the financial support from the Innovation Foundation of Director (0707d81001).

\section{References}

1. Terabe, K.; Yamaguchi, S.; Iguchi, Y.; Imai, A. Solid State Ionics 1990, 40-41, 111.

2. Oshima, T.; Kajita, M.; Okuno, A. International Journal of Applied Ceramic Technology 2004, 1, 269.

3. Sakka, Y.; Honda, A.; Suzuki, T. S.; Moriyoshi, Y. Solid State Ionics 2004, 172, 341.

4. Morgan, P. E. D. Mater. Res. Bull. 1976, 11, 233.

5. Jayaraman, V.; Gnanasekaran, T.; Periaswami, G. Mater. Lett. 1997, 30, 157.

6. Kutty, T. R. N.; Jayaraman, V.; Periaswami, G. Mater. Res. Bull. 1996, $31,1159$.

7. Subasri, R. Mater. Sci. Eng., B 2004, 112, 73.

8. Subasri, R.; Mathews, T.; Sreedharan, O. M.; Raghunathan, V. S. Solid State Ionics 2003, 158, 199.

9. Pekarsky, A.; Nicholson, P. S. Mater. Res. Bull. 1980, 15, 1517.

10. Park, H. C.; Lee, Y. B.; Lee, S. G.; Lee, C. H.; Kim, J. K.; Hong, S. S.; Park, S. S. Ceram. Int. 2005, 31, 293.

11. Mathews, T. Mater. Sci. Eng., B 2000, 78, 39.

12. Thompson, S.; Shirtcliffe, N. J.; O'Keefe, E. S.; Appleton, S.; Perry, C. C. J. Magn. Magn. Mater. 2005, 292, 100. 